\title{
Maternal socio-demographic determinants and fetal outcome of intrauterine growth restriction
}

\author{
Arpita Singh*, Ambujam K.
}

Department of Obstetrics and Gynecology, Government Medical College, Thrissur, Kerala, India

Received: 11 July 2018

Accepted: 06 August 2018

\section{*Correspondence:}

Dr. Arpita Singh,

E-mail: arpitasingha47@yahoo.com

Copyright: () the author(s), publisher and licensee Medip Academy. This is an open-access article distributed under the terms of the Creative Commons Attribution Non-Commercial License, which permits unrestricted non-commercial use, distribution, and reproduction in any medium, provided the original work is properly cited.

\begin{abstract}
Background: Intrauterine Growth Restriction is a major neonatal health issue. It is associated with increased risk of perinatal morbidity and mortality. Maternal factors are the major contributing factors of IUGR and studying these factors can help in preventing IUGR and reducing perinatal mortality. The objective is to study the maternal sociodemographic risk factors associated with Intra uterine growth restriction.

Methods: This is a Case-control study conducted in the Department of Obstetrics and Gynaecology, GMC Thrissur. 115 cases of Intra Uterine Growth Restriction were compared to 115 controls. Data was collected by interviewing the mother using structured questionnaire which is pretested and by persual of antenatal records. Intra Uterine Growth Restriction is defined as occurring if the sonographic estimated fetal weight $<10$ th percentile for that gestational age. Chi Square test was used for the analysis of data.

Results: Low socio-economic status and malnutrition $(\mathrm{BMI}<18.5)$ were significant socio-demographic factors associated with fetal growth restriction. Mean birth weight in IUGR group was $1.8 \mathrm{~kg}$ compared to $2.9 \mathrm{~kg}$ in control group. Female fetuses were more commonly associated with IUGR. Intra Uterine Growth Restricted babies had lower Apgar scores $(<7)$ and had more chances for NICU admission.

Conclusions: By studying the maternal risk factors associated with Intra Uterine Growth Restriction, we could identify the high-risk group. Early predictive studies could be done in these high-risk pregnancies with focus on good antenatal care to reduce the problem of IUGR in the community.
\end{abstract}

Keywords: Intra uterine growth restriction, Risk factors, small for gestational age

\section{INTRODUCTION}

IUGR is one of the most common and complex problems in modern obstetrics. It is observed in about $23.8 \%$ of the newborns and approximately 30 million babies every year. Nearly $75 \%$ of the affected babies are born in Asia. ${ }^{1}$ IUGR is associated with increased risk of perinatal morbidity and mortality.

When the sonographic estimated fetal weight is less than $10^{\text {th }}$ percentile for that gestational age it is defined to be Intra Uterine Growth Restriction. ${ }^{2}$ Fetal growth is a highly complex process and is determined by the genetic growth potential, ability of mother to supply necessary substrates required for growth, and the ability of placenta to transport these substrates.

About 50-60\% of growth restricted newborns are not pathologically restricted but are constitutionally small because of normal biological factors. ${ }^{3,4}$

True IUGR is associated with signs of abnormal fetoplacental circulation and has poor perinatal outcome whereas constitutionally small fetus has normal fetoplacental function and normal perinatal outcome. According to the Barcelona Centre of Maternal-Fetal 
medicine, Fetal Growth Restriction is diagnosed in the presence of any of the factors associated with poor perinatal outcome which includes abnormal cerebroplacental ratio, abnormal uterine artery Doppler and $\mathrm{EFW}<3^{\text {rd }}$ percentile. $^{5}$

The most common condition implicated in IUGR is alteration in the uteroplacental blood flow and the most common fetal condition is chromosomal abnormalities. Maternal factors leading to IUGR include sociodemographic factors like low socioeconomic status, pre-pregnancy weight, maternal education, inadequate prenatal care, extremes of age, short inter-pregnancy interval, smoking, alcohol.

Maternal biological factors affecting IUGR include preeclampsia, chronic HTN, DM with vasculopathy, anaemia, cardiac disease, chronic renal disease and haemoglobinopathies. Fetal infections and chromosomal abnormalities contribute to $10-15 \%$ of the cases of IUGR. ${ }^{6}$

IUGR fetuses are associated with many complications. Most common being prenatal and intrapartum hypoxia and acidosis when the cause is placental insufficiency. The main antepartum complications are fetal distress, stillbirth, oligoamnios.

Intrapartum complications include hypoxia, acidosis and high rate of Caesarean Section. Neonatal complications are Respiratory Distress Syndrome, Meconium Aspiration Syndrome, Intraventricular Haemorrhage, hypoglycemia, Hypoxic Ischemic Encephalopathy, hypocalcemia, hyperbilirubinemia, Necrotising Enterocolitis. Long term complications of IUGR include neurodevelopmental delay and cerebral palsy. Identifying the factors responsible for IUGR is important, so that early interventions can be taken to improve the perinatal outcome.

\section{METHODS}

This is a case-control study carried out in the Department of Obstetrics and Gynaecology, Thrissur from 1st January 2015 to 31st December 2015 over 1year period. 115 cases were compared to 115 controls.

Women with IUGR diagnosed by USG showing Estimated Fetal Weight <10th percentile for the gestational age were taken as cases. Controls were taken along with the cases having normal sonographic estimated fetal weight. Controls were matched for maternal age.

Singleton pregnancies more than or equal to 32 weeks were included in the study. Women with multiple pregnancy, fetal anomalies and IUGR less than 32 weeks were excluded from the study.
Data was collected by interviewing the mother using structured questionnaire and by perusal of antenatal records. Age, socioeconomic status, occupation, booking status, residence, antenatal checkups, BMI, interpregnancy interval and addictions was taken into account. Mode of delivery and baby details like neonatal survival, birth weight, gender, APGAR scores and NICU admission was also recorded. Data was analyzed using parameters like mean and Chi square test.

\section{RESULTS}

Total 115 cases were compared to 115 controls. The mean birth weight in the IUGR group was $1.8 \mathrm{~kg}$ compared to $2.9 \mathrm{~kg}$ in the control group which was statistically significant difference.

Cases and controls were matched for maternal age. The mean maternal age was $26 \pm 5.3$ years. Majority of the patients were between 20-34 years.

Mean BMI was 22.3 among cases compared to 25.4 in the control group. Malnutrition was a significant risk factor for IUGR with $27 \%$ of the women in the IUGR group having low BMI compared to $0.9 \%$ in the controls.

Women in the IUGR group had significantly lower BMI, belonged to low socio-economic status and majority were referred from outside as compared to women in the control group. Low socioeconomic status was found to be significantly associated with IUGR $(\mathrm{p}=0.0001)$.

More than $75 \%$ of the women in both the groups belonged to rural areas and were housewives. Both the groups were comparable.

Majority of the women in both the groups had regular antenatal checkups and no significant difference was observed between the groups.

More than $90 \%$ of the women had inter-pregnancy interval more than 1year and had spontaneous conception. No significant association was found between infertility treatment and IUGR.

Approximately $50 \%$ of the cases were induced and had Caesarean delivery. Female babies were significantly associated with IUGR ( $\mathrm{p}=0.03$ ). Three IUGR babies were stillborn and one died in the neonatal period.

There were no intrauterine or neonatal deaths in the control group. APGAR score of less than 7 was seen in $7 \%$ of IUGR babies compared to $0 \%$ in AGA babies which was statistically significant difference. $50 \%$ of the IUGR babies were admitted in NICU for low birth weight care. 
Table1: Maternal socio-demographic factors of IUGR.

\begin{tabular}{|c|c|c|c|c|c|c|c|}
\hline \multirow{2}{*}{ Risk factors } & \multirow{2}{*}{ Categories } & \multicolumn{2}{|c|}{ Cases } & \multicolumn{2}{|c|}{ Controls } & \multirow[t]{2}{*}{$\chi^{2}$} & \multirow[t]{2}{*}{ P value } \\
\hline & & Number & Percent & Number & Percent & & \\
\hline \multirow{5}{*}{ BMI } & $<18.5$ & 31 & 27.0 & 1 & 0.9 & \multirow{5}{*}{35.22} & \multirow{2}{*}{$0.000^{*}$} \\
\hline & $18.5-24.9$ & 54 & 47.0 & 59 & 51.8 & & \\
\hline & $25-29.9$ & 22 & 19.1 & 40 & 35.1 & & \\
\hline & $30-34.9$ & 7 & 6.1 & 12 & 10.5 & & \\
\hline & $>35$ & 1 & 0.9 & 2 & 1.8 & & \\
\hline \multirow{2}{*}{$\begin{array}{l}\text { Socio-economic } \\
\text { status }\end{array}$} & BPL & 83 & 72.2 & 64 & 55.6 & \multirow{2}{*}{6.80} & \multirow{2}{*}{$0.009 *$} \\
\hline & APL & 32 & 27.8 & 51 & 44.3 & & \\
\hline \multirow{2}{*}{ Residence } & Urban & 31 & 27.0 & 25 & 21.7 & \multirow{2}{*}{0.85} & \multirow{2}{*}{0.357} \\
\hline & Rural & 84 & 73.0 & 90 & 78.3 & & \\
\hline \multirow[b]{3}{*}{ Occupation } & Housewife & 92 & 80.0 & 100 & 87.0 & \multirow{3}{*}{2.39} & \multirow{3}{*}{0.303} \\
\hline & $\begin{array}{l}\text { Manual } \\
\text { labourer }\end{array}$ & 13 & 11.3 & 10 & 8.7 & & \\
\hline & $\begin{array}{l}\text { Skilled } \\
\text { worker }\end{array}$ & 10 & 8.7 & 5 & 4.3 & & \\
\hline \multirow{3}{*}{ Antenatal check ups } & Regular & 111 & 96.5 & 113 & 98.3 & \multirow{3}{*}{2.02} & \multirow{3}{*}{0.365} \\
\hline & Irregular & 2 & 1.7 & 2 & 1.7 & & \\
\hline & No ANC & 2 & 1.7 & 0 & 0.0 & & \\
\hline \multirow{3}{*}{ Booking status } & Booked & 38 & 33.0 & 74 & 64.3 & \multirow{3}{*}{23.54} & \multirow{3}{*}{$0.000^{* *}$} \\
\hline & Booked out & 75 & 65.2 & 41 & 35.7 & & \\
\hline & Un booked & 2 & 1.7 & 0 & 0.0 & & \\
\hline \multirow{2}{*}{$\begin{array}{l}\text { Inter-pregnancy } \\
\text { interval }\end{array}$} & $<1$ year & 3 & 5.0 & 1 & 1.3 & \multirow{2}{*}{1.67} & \multirow{2}{*}{0.197} \\
\hline & $\geq 1$ year & 57 & 95.0 & 77 & 98.7 & & \\
\hline \multirow{3}{*}{ Addiction } & $\begin{array}{l}\text { No } \\
\text { addiction }\end{array}$ & 102 & 88.7 & 103 & 89.5 & \multirow{3}{*}{2.04} & \multirow{3}{*}{0.361} \\
\hline & $\begin{array}{l}\text { Passive } \\
\text { smoking }\end{array}$ & 11 & 9.6 & 12 & 10.5 & & \\
\hline & $\begin{array}{l}\text { Active } \\
\text { smoking }\end{array}$ & 2 & 1.7 & 0 & 0.0 & & \\
\hline \multirow{2}{*}{ Infertility treatment } & $\begin{array}{l}\text { Treatment } \\
\text { taken }\end{array}$ & 6 & 5.2 & 4 & 3.5 & & \\
\hline & $\begin{array}{l}\text { No } \\
\text { treatment }\end{array}$ & 109 & 94.8 & 111 & 96.5 & 0.42 & 0.518 \\
\hline & Male & 49 & 42.6 & 65 & 56.5 & & $0035^{*}$ \\
\hline Gender of baby & Female & 66 & 57.4 & 50 & 43.5 & 4.45 & 0.035 \\
\hline
\end{tabular}

Table 2: Comparison of birth weight.

\begin{tabular}{|c|c|c|c|c|c|c|}
\hline \multirow[b]{2}{*}{ Birth weight } & \multicolumn{2}{|l|}{ Case } & \multicolumn{2}{|l|}{ Control } & \multirow[t]{2}{*}{$x^{2}$} & \multirow[t]{2}{*}{ p value } \\
\hline & Number & Percent & Number & Percent & & \\
\hline$<1 \mathrm{~kg}$ & 5 & 4.3 & 0 & 0.0 & \multirow{5}{*}{185.49} & \multirow{5}{*}{$0.000^{*}$} \\
\hline $1-1.5 \mathrm{~kg}$ & 33 & 28.7 & 0 & 0.0 & & \\
\hline $1.5-2 \mathrm{~kg}$ & 37 & 32.2 & 2 & 1.7 & & \\
\hline $2-2.5 \mathrm{~kg}$ & 40 & 34.8 & 12 & 10.4 & & \\
\hline$>2.5 \mathrm{~kg}$ & 0 & 0.0 & 101 & 87.8 & & \\
\hline Mean \pm SD & $1.8 \pm 0.4$ & & $2.9 \pm 0.4$ & & & \\
\hline
\end{tabular}

\section{DISCUSSION}

The incidence of IUGR varies depending on the population examined from 4 to $7 \%$ in developed countries and up to $30 \%$ in developing countries. ${ }^{7}$ The prevalence of IUGR in our institution during the study period was $24.9 \%$ which is comparable to study by
Chauhan SP et al in which the prevalence of IUGR was observed to be $22 \%{ }^{8}$

Majority of the women belonged to low socioeconomic category. This is due to the fact that our institution provides health facilities to the lower strata of the society. The incidence of IUGR was found to be statistically 
higher in lower socioeconomic group which was comparable to study by Motghare DD et al in which mothers who belonged to low socioeconomic class were 12.96 times more likely to have an IUGR baby. ${ }^{9}$
Maternal malnutrition is significantly associated with IUGR which is consistent with Kramer's meta-analysis and various other studies. ${ }^{10-12}$

Table 3: Outcome of IUGR fetuses.

\begin{tabular}{|c|c|c|c|c|c|c|c|}
\hline \multirow{2}{*}{ Fetal outcome } & & \multicolumn{2}{|l|}{ Case } & \multicolumn{2}{|l|}{ Control } & \multirow[t]{2}{*}{$\chi^{2}$} & \multirow[t]{2}{*}{ p value } \\
\hline & & Number & Percent & Number & Percent & & \\
\hline \multirow{3}{*}{$\begin{array}{l}\text { Perinatal } \\
\text { survival }\end{array}$} & Live born & 111 & 96.5 & 115 & 100 & \multirow{3}{*}{4.07} & \multirow{3}{*}{0.131} \\
\hline & Still born & 3 & 2.6 & 0 & 0.0 & & \\
\hline & NND & 1 & 0.87 & 0 & 0.0 & & \\
\hline \multirow{4}{*}{ APGAR at 5} & 0 & 3 & 2.6 & 0 & 0.0 & \multirow{4}{*}{8.288} & \multirow{4}{*}{$0.040^{*}$} \\
\hline & $<5$ & 1 & 0.9 & 0 & 0.0 & & \\
\hline & $5-7$ & 4 & 3.5 & 0 & 0.0 & & \\
\hline & $>7$ & 107 & 93 & 115 & 100.0 & & \\
\hline \multirow{2}{*}{ NICU admission } & Yes & 56 & 50.5 & 4 & 3.5 & \multirow{2}{*}{63.91} & \multirow{2}{*}{$0.000^{*}$} \\
\hline & No & 55 & 49.5 & 111 & 96.5 & & \\
\hline
\end{tabular}

*Significant at 0.05 level

More than $70 \%$ of women in both the groups were from rural areas due to the fact that $70 \%$ of the population lives in rural areas in India and there may be an increased referral of patients from these areas. Majority of the women had regular antenatal checkups in both the groups. This can be attributed to the high literacy rate and greater health awareness among women in the state. Both the groups are comparable and irregular antenatal care could not be considered as a significant risk factor in this study.

Majority of the women in the IUGR group were referred from peripheral hospitals compared to controls $(p=0.0001)$. The higher percentage of referrals reflects the fact that our institution is a tertiary centre catering to a large population and patients are referred for management of obstetric complications and for better neonatal intensive care facilities.

No significant difference was seen in inter-pregnancy interval and infertility treatment between cases and controls. It is comparable to study by Isaksson $\mathrm{R}$ et al which showed no difference in the incidence of low birth weight in women with infertility treatment. ${ }^{13}$

In our population usually addictions like smoking, alcoholism, drugs etc. are quite uncommon among females; hence not found as a contributing factor.

Mean birth weight in the IUGR group was $1.8 \mathrm{~kg}$ compared to $2.9 \mathrm{~kg}$ in the control group which was statistically significant. A study by Sehested LT et al showed mean birth weight of $1.6 \mathrm{~kg}$ which was comparable to present study. ${ }^{14}$ Female babies were more likely to be growth restricted compared to male babies. This finding was consistent with the study by Spinillo A et al which showed IUGR to be more frequent in female fetuses. $^{15}$

There were 3 stillbirths and 1 NND in IUGR group as compared to nil intrauterine or neonatal deaths in control group. The overall survival rate among IUGR babies was $96.5 \%$ whereas in the control group it was $100 \%$.

APGAR score at 5 minutes is related to neurodevelopmental outcome of the newborn. Significant difference was seen in the APGAR scores and NICU admission in IUGR babies compared to AGA babies. Nearly half of the IUGR babies required NICU admission.

To summarise, low socio-economic status and maternal malnutrition were significant risk factors for IUGR.

\section{CONCLUSION}

This study provides information on the sociodemographic risk factors for IUGR which can be used in better planning of maternal and child health services. Malnutrition and poverty are modifiable risk factors. Dietary supplementation in the reproductive age group, frequent antenatal checkups and assessment of complications will be beneficial in reducing the prevalence of IUGR in the community which could ultimately help in reducing infant mortality and morbidity.

\section{ACKNOWLEDGMENTS}

Authors would like to thank the Department of Obstetrics and Gynaecology, Thrissur for their cooperation and 
support and all the patients without whom this study might not have been materialized.

Funding: No funding sources Conflict of interest: None declared

Ethical approval: The study was approved by the Institutional Ethics Committee

\section{REFERENCES}

1. Kleijer ME, Dekker GA, Heard AR. Risk factors for intrauterine growth restriction in a socioeconomically disadvantaged region. J Maternal-Fetal Neonat Medi. 2005;18(1):23-30.

2. Fetal growth disorders. In Williams Obstetrics. $24^{\text {th }}$ ed. New York, NY: Mc Graw Hill; 2013:872-890.

3. Ott WJ. The diagnosis of altered fetal growth. Obstet Gynecol Clinic North Am. 1988;15(2):237-63.

4. Wilcox AJ. Intrauterine growth retardation: beyond birthweight criteria. Early Hum Dev. 1983;8(34):189-93.

5. Figueras F, Gratacos E. Update on the Diagnosis and Classification of Fetal Growth Restriction and proposal of a Stage-Based Management Protocol. Fetal Diagn Ther. 2014;36(2):86-98.

6. Fernando Arias, Shirish N Daftary, Amarnath G Bhide. Fetal Growth Restriction. In Practical Guide to High Risk Pregnancy and Delivery-A South Asian Prespective. $3^{\text {rd }}$ ed. Elsevier; 2008:105-34.

7. Vandenbosche RC, Kirchner JT. Intrauterine growth retardation. Am Fam Physician. 1998;58:1384-94.

8. Chauhan SP, Taylor M, Shields D, Parker D, Scardo JA, Magann EF. Intrauterine growth restriction and oligohydramnios among high-risk patients. Am J Perinatol. 2007;24(4):215-21.

9. Motghare DD, Frederick SV, Pawaskar M, Kulkarni MS. Maternal determinants of intrauterine growth restriction in Goa, India: a case-control study. Global J Medic Public Health. 2014;3(1):O8.

10. Kramer MS. Determinants of low birth weight: methodological assessment and meta-analysis. Bulletin WHO.1987;65(5):663-737.

11. Godfrey K, Robinson S, Barker DJ, Osmond C, Cox $\mathrm{V}$. Maternal nutrition in early and late pregnancy in relation to placental and fetal growth. BMJ. 1996;312(7028):410-4.

12. Rondo PHC, Abbott R, Rodrigues LC, Tomkins AM. The influence of maternal nutritional factors on intrauterine growth retardation in Brazil. Paediatr Perinat Epidemiol. 1997;11(2):152-66.

13. Isaksson R, Gissler M, Tiitinen A. Obstetric outcome among women with unexplained infertility after IVF: a matched case- control study. Hum Reprod. 2002;17(7):1755-61.

14. Sehested LT, Pedersen. Prognosis and risk factors for intrauterine growth retardation. Dan Med J. 2014;61(4):A4826.

15. Spinillo A, Capuzzo E, Nicola S, Colonna L, Lasci $\mathrm{A}$, Zara C. Interaction between fetal gender and risk factors for fetal growth retardation. Am J Obstet Gynecol. 1994;171(5):1273-7.

Cite this article as: Singh A, Ambujam K. Maternal socio-demographic determinants and fetal outcome of intrauterine growth restriction. Int J Reprod Contracept Obstet Gynecol 2018;7:3843-7. 